\title{
In situ atomic force microscope observations of a dissolution-crystallisation reaction: The phosgenite-cerussite transformation
}

\author{
C. M. Pina, ${ }^{*, 1}$ L. Fernández-Díaz, ${ }^{2}$ M. Prieto, ${ }^{3}$ and A. Putnis ${ }^{1}$ \\ ${ }^{1}$ Institut für Mineralogie, Universität Münster, Correnstrasse 24, D-48149 Münster, Germany \\ ${ }^{2}$ Dpto. Cristalografía y Mineralogía, Universidad Complutense de Madrid, E-28040 Madrid, Spain \\ ${ }^{3}$ Dpto. Geología, Universidad de Oviedo, E-33005 Oviedo, Spain
}

\begin{abstract}
The dissolution-reprecipitation reaction of phosgenite $\left(\mathrm{Pb}_{2} \mathrm{Cl}_{2} \mathrm{CO}_{3}\right)$ to cerussite $\left(\mathrm{PbCO}_{3}\right)$ has been observed in situ in a fluid cell of an atomic force microscope (AFM). The (001) face of phosgenite, in contact with static carbonated aqueous solutions, rapidly begins to dissolve. AFM observations show that dissolution occurs by generation and spread of square-shaped etch pits with sides parallel to $\langle 110\rangle$ directions. The dissolution of the $\langle 110\rangle$ steps is isotropic and the etch pits therefore remain square shaped during the dissolution process, as dictated by the existence of a fourfold axis perpendicular to the phosgenite (001) face. Two types of $\langle 110\rangle$ etch pits were found: short-lived shallow pits, of one unit cell depth $(8.8 \AA)$, and deep pits, which rapidly reach depths between 10 and $60 \mathrm{~nm}$. A few minutes after the dissolution begins, only the deep pits remain and subsequent dissolution of the phosgenite (001) surface proceeds by increasing their width and depth. The increase of $\mathrm{Pb}^{2+}$ and $\mathrm{CO}_{3}^{2-}$ concentration in the aqueous solution as a consequence of the dissolution sharply increases the supersaturation for $\mathrm{PbCO}_{3}$. As a result, after a certain incubation time, cerussite crystals nucleate on the phosgenite (001) surface and a coupled process of dissolution-crystallisation starts. Cerussite crystals, which grow by a spiral-growth mechanism, distort the concentration field around them. As a consequence, phosgenite dissolution is accelerated in the proximity of such growing cerussite individuals and both the formation of new deep etch pits and the development of irregular dissolution fronts are observed. Further phosgenite dissolution leads to an increase of cerussite nucleation and growth rates, in such a way that this dissolution-crystallisation phenomenon can be considered as an autocatalytic process.
\end{abstract}

\section{INTRODUCTION}

The transformation of one solid mineral phase to another characterizes many geological processes in which changing physical and chemical conditions lead to the destabilization of one phase and the growth of another. Such transformations may occur in the solid state by a structural rearrangement, or alternatively may involve the dissolution of one phase and the precipitation of the other. During diagenesis and metamorphism the latter process is generally thought to be dominant, and the role of the intergranular fluids is of fundamental importance. Although the mechanism and kinetics of solid state transformations have been studied for many years, solutionprecipitation reactions are experimentally more difficult to constrain. When there is a change in chemical composition involved the components may be exchanged across a thin layer of interstitial fluid, as in the replacement reactions so common in metamorphism, e.g., phyllosilicates replacing amphiboles and pyroxenes. The kinetics of such reactions will depend on both the rate of dissolution of the reactant phase and the rate of growth of the product, although it is unlikely that these two rates can be treated independently when considering the overall rate, especially if nucleation of the product takes place on the surface of the reactant. The coupling between dissolution and reprecipitation rates has been considered in cases of pseudomorphic replacement (Nahon and Merino, 1997; Merino and Dewers, 1998) where it was concluded that intergranular stress

* Address reprint requests to C. M. Pina (pina@nwz.uni-muenster.de). generated by the growth of the product phase can regulate reaction rates. Coupling has also been considered for cases of dissolution-diffusion-crystallisation processes (Fisher and Lasaga, 1981) where stress was not considered is a controlling factor. In this paper we describe an experimental dissolution reprecipitation reaction in free fluid, in the absence of significant stress and without restricted diffusion paths.

The rates of dissolution and crystal growth of many watersoluble phases can be observed at a molecular scale in situ using atomic force microscopy AFM (Hillner et al., 1992; Bosbach et al., 1998), and so this technique should also be applicable for observing the mechanisms of dissolution-reprecipitation reactions. To investigate this possibility we chose the transformation of phosgenite $\left(\mathrm{Pb}_{2} \mathrm{Cl}_{2} \mathrm{CO}_{3}\right)$ to cerussite $\left(\mathrm{PbCO}_{3}\right)$ in the presence of an aqueous fluid. This reaction proceeds at a measurable rate, and is also geochemically relevant. Interest in the aqueous geochemistry of lead has increased considerably in the last decades as a consequence of the potential toxic hazard of this material, and its occurrence in natural waters and soils (Hem, 1976; Sæther et al., 1988). These studies usually deal with thermodynamic calculations on the behaviour of lead in aqueous media (aqueous lead complexes, reaction pathways, interactions with organic matter in the soil, etc.). However, studies on the microscopic mechanisms which determine the dissolution kinetics of lead minerals are scarce.

In natural processes lead can be dissolved from primary minerals and transported in solution over considerable distances, or incorporated into secondary minerals. Phosgenite and 
Table 1. The initial concentrations of $\mathrm{Na}_{2} \mathrm{CO}_{3}$ and the initial $\mathrm{pH}$ of the aqueous solutions used in the experiments.

\begin{tabular}{|c|c|c|c|c|}
\hline $\begin{array}{c}\text { Dissolving solution: Initial } \\
\text { concentration } \mathrm{Na}_{2} \mathrm{CO}_{3}(\mu \mathrm{mol} / \mathrm{L})\end{array}$ & $\begin{array}{l}\text { Initial } \mathrm{pH} \text { of the } \\
\text { dissolving solution }\end{array}$ & $\begin{array}{l}\text { Dissolved phosgenite at } \\
\text { cerussite saturation }(\mu \mathrm{mol} / \mathrm{L})\end{array}$ & $\begin{array}{l}\mathrm{pH} \text { at cerussite } \\
\text { saturation }\end{array}$ & $\begin{array}{l}\boldsymbol{\beta}_{\text {-slope }}^{\mathrm{a}} \text { at cerussite } \\
\text { saturation }\left(\mu \mathrm{mol} / \mathrm{L}^{-1}\right)\end{array}$ \\
\hline 0.0 & 5.7 & 8.87 & 6.83 & •.181 \\
\hline 6.0 & 6.4 & 5.60 & 6.89 & 0.187 \\
\hline 10.0 & 6.7 & 4.20 & 6.93 & 0.220 \\
\hline 25.0 & 7.1 & 1.56 & 7.11 & 0.478 \\
\hline
\end{tabular}

${ }^{a}$ Slope of the curve that represents the cerussite supersaturation as a function of the dissolved phosgenite.

cerussite are supergene minerals formed by the action of meteoric waters on primary lead minerals, mainly galena. The transformation of phosgenite into cerussite is a common phenomenon, frequently observed in such secondary lead deposits. The relative stability of phosgenite and cerussite, and hence the conditions for the development of such a transformation, depends dramatically on the $\mathrm{pH}$ in the medium (Edwards et al., 1992). Although the specific value depends on the whole chemis of the system, in general at a $\mathrm{pH}$ higher than $\sim 4.5$ an aqueous solution saturated with respect to phosgenite is highly supersaturated with respect to cerussite, which means that phosgenite is unstable in this $\mathrm{pH}$ range. Soil waters generally have $\mathrm{pH}$ values as low as 4 or 5 but after percolation through carbonate rocks meteoric waters, previously charged with oxygen from the a mosphere, can dissolve significant amounts of carbonate ions and increase their $\mathrm{pH}$. By reaction with these waters, primary lead minerals can directly oxidise to the relatively insoluble cerussite (Park and MacDiannid, 1970). However, when the oxidation process occurs at a low $\mathrm{pH}$, in aqueous chloride media, a considerable number of lead chlorides and double salts can crystallise. Phosgenite is one of the minerals that commonly forms under such conditions (AbdulSamad et al., 1982). In most cases, a subsequent phosgenitecerussite ransformation can be observed. The geological evidence for these processes is convincing in cerussite ores, where cores of primary lead minerals (galena) are rimmed with cerussite and epitactic relationships between phosgenite and cerussite have been described (Lattani and Tanelli, 1978; Von Vultée, 1950).

Crystal growth experiments carried out in a silica gel medium (Pina et al., 1996) indicate that the phosgenite-cerussite transformation occurs by a solution-precipitation reaction. In the chemical literature such transformations have also been referred to as solvent-mediated recrystallisation processes (Cardew and Davey, 1985). The existence of a thin film of solution between both phases allows the dissolution of phosgenite simultaneously with the growth of an oriented aggregate of cerussite crystals.

In this paper we describe an in situ AFM study of the phosgenite-cerussite transformation in aqueous media and relate the observations to thermodynamic calculations of the physico-chemical evolution (concentration of aqueous species and saturation states for the lead solid phases) of the aqueous solution during the phosgenite dissolution process. Microtopographic AFM observations of phosgenite (001) faces during this ransformation provide information about the mechanism of the solvent-mediated dissolution-recrystallisation process at a molecular scale. In addition, monitoring of the development of the transformation in real time allows kinetic data to be obtained of both phosgenite dissolution and cerussite nucleaton. This is the first ime, to the authors' knowledge, that a dissolution-crystallisation process has been followed by AFM.

\section{EXPERIMENTAL PROCEDURE}

In situ phosgenite-cerussite transformation AFM experiments were carried out at $25 \mathrm{C}$ in a commercially available fluid cell of a Digital Instrument Multimode apparatus. All the AFM images were taken in constant force mode while displaying both height and deflection signals of the cantilever. The samples used as a substrate were optically clear natural phosgenite crystals from the Toussit mine, Oiujda (Morocco). Phosgenite specimens $\left(\sim 5 \mathrm{~mm}^{3}\right)$ were freshly cleaved on $(001)$ before each experiment and mounted in the fluid cell of the AFM. In order to promote the dissolution-transformation process of phosgenite into cerussite, phosgenite $(\mathbf{0 0 1})$ faces were exposed to both pure water and $\mathrm{Na}_{2} \mathrm{CO}_{3}$ aqueous solutions (static solutions in the fluid cell with no flow through the system). The volume of fluid in the cell is $\sim 50 \mu \mathrm{L}$. The initial $\mathrm{pH}$ of the system was set by using different concentrations of $\mathrm{Na}_{2} \mathrm{CO}_{3}$ in the aqueous solution. Table 1 shows the initial concentrations of $\mathrm{Na}_{2} \mathrm{CO}_{3}$ and the initial $\mathrm{pH}$ of the aqueous solutions used in these experiments. In all cases de-ionized water and reagent-grade (Merck) chemicals were used. The solutions were prepared at atmospheric $\mathrm{pCO}_{2}$.

After the transformation experiments, crystals were removed from the AFM fluid cell. X-ray diffraction of the surface in a Phillips PW-1050 diffractometer using monochromatic $\mathrm{Cu} K_{\alpha}$ radiation confirmed it as a mixture of phosgenite and cerussite.

\section{AFM OBSERVATIONS}

\subsection{Microtopography of Phosgenite (001) Surfaces}

Phosgenite crystals (space group: $P 4 / \mathrm{mbm} ; \boldsymbol{a}=\boldsymbol{b}=8.160$ $\AA$ and $c=8.883 \AA$; Giuseppeti and Tadini, 1974) have a relatively good cleavage on (001). Freshly cleaved phosgenite (001) faces observed by AFM show atomically flat terraces and a number of monomolecular steps running along different crystallographic directions. The most numerous steps observed are parallel to $\langle 110\rangle$ and $\langle 100\rangle$, Other step directions (e.g., $\langle 120\rangle$ and $\langle 130\rangle)$ can be also found. Orientation of cleavage steps and step density are controlled by the distribution of $\langle 110\rangle$ chains of $\mathrm{Pb}-\left(\mathrm{Cl}, \mathrm{CO}_{3}\right)-\mathrm{Pb}$ bonds (PBCs) (Pina et al., 1996) within the slice $\mathbf{d}_{001}$ and also by the velocity of propagation of the cleavage front. The dependence of the surface topography of a cleaved surface on the cleavage velocity has also been noted by Overney et al. (1992). Frequently, cleavage surfaces also show one-unit-cell deep square pits, whose shape is defined by edges parallel to $\langle 110\rangle$ directions. These are flat-bottomed pits and their existence may be related to the presence of point defects and/or inclusions in the original crystal (Sangwal et al. 1977). Both the different orientation of the cleavage steps and the distribution of the square pits on the surface can result in very complex microtopography. In addition, phosgenite (001) 

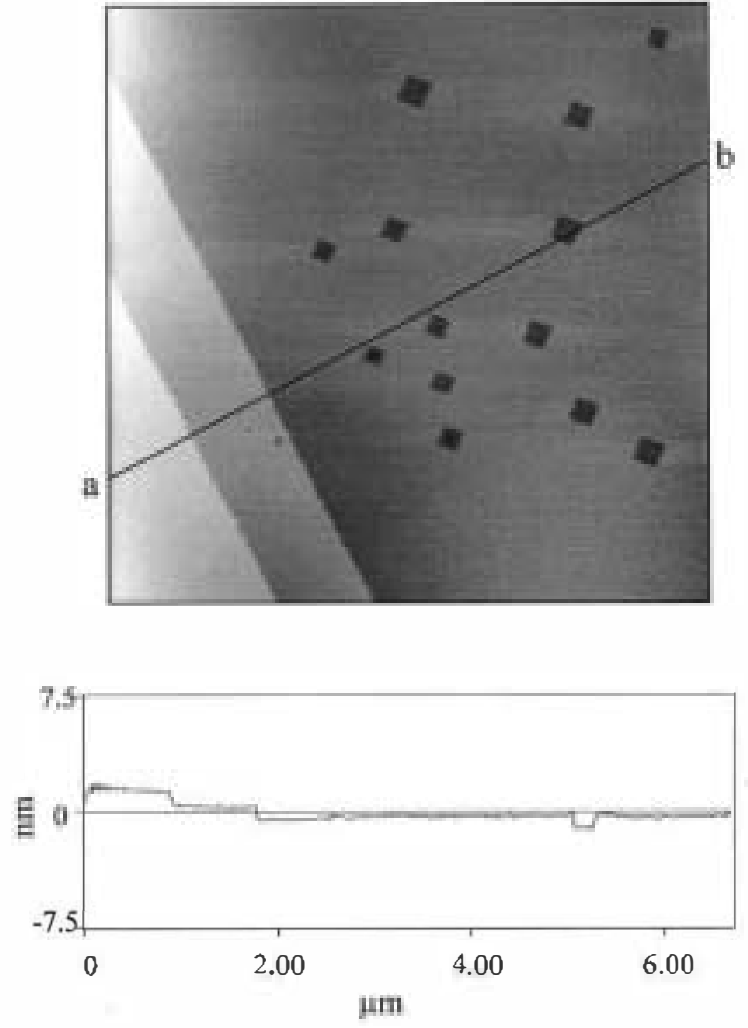

Fig 1 (a) Atomic force microscope image of a freshly cleaved (\$01) surface of hos enite. The image was taken in constant force mode while displaying the cant lever height signal. The scan area was $6 \times 6$ $\mu \mathrm{m}^{2}$ Monomolecular steps parallel to $\langle 100\rangle$ and square pits bound by $\langle 110\rangle$ can be observed. (b) Profile along the indicated $\boldsymbol{a}$ - $\boldsymbol{b}$ line in (a) showing tw steps of $8 \mathbb{A}$ height and one pit one unit cell deep ( 8 A)

cleaved faces exhibit a relatively high reactivity to the atmospheric humidity. Atomic force microscope images frequently reveal signs of slight dissolution on the terraces and step edges a few minutes after the cleavage process. Such slight rearrangement of the phosgenite (001) surfaces demonstrates their unstable nature IIIder atmospheric conditions. Similar observations relating to the mobility of calcite surfaces in air have also been made by Stipp et al. (1996)).

Figure 1 a shows a typical phosgenite (001) cleavage surface with two [100] steps and $\langle 110\rangle$ bounded pits. In Fig. 1b a section profile taken perpendicular to the [100] steps is shown. The height of the cleavage steps and the depth of the squareshaped pits are both $8.8 \AA$, i.e., the height of one unit cell.

\subsection{Phosgenite Dissolntion}

Phosgenite (001) surfaces in contact with pure water or $\mathrm{Na}_{2} \mathrm{CO}_{3}$ solutions rapidly begin to dissolve. Dissolution essentially occurs by generation and widening of etch pits on the flat terraces. From the very beginning of the process, two different types of pits can be distinguished on the surface: shallow pits and deep pits. The shallow pits are one or two unit-cells deep and may be related to point defects on the surface. The deep pits rapidly reach depths between 10 and $60 \mathrm{~nm}$ and may be associated with the emergence of dislocations. The relation between the shape of etch pits and the inclination of dislocations with respect to the dissolving surface have been extensively described by Sangwal, (1987). In the case of screw dislocations the connecting line between the base of a pyramidal pit and its apex is always tangent to the dislocation line. Consequently, synunetrical pits correspond to dislocations perpendicular to the dissolving surface, while asynunetrical pits indicate that dislocations are oblique with respect to the surface. All the deep etch pits observed on phosgenite (001) faces exhibit a symmetrical pyramidal shape, suggesting that they are related to screw dislocations perpendicular to that surface, i.e., dislocation lines munning along [001].

In the initial stages of dissolution, the microtopography of the surface is characterised by a high density of shallow pits $\left(\sim 10 \mu \mathrm{m}^{-2}\right)$ and a low density of deep pits $\left(\sim 0.5 \mu \mathrm{m}^{-2}\right)$. Both show the characteristic square shape with sides parallel to $\langle 110\rangle$ directions described in Sect. 3.1. The shape and orientation of etch pits are consistent with the existence of a fourfold axis perpendicular to the phosgenite (001) face. The widening of these pits and their morphology is controlled by the retreat of 〈110) monomolecular steps. Since such steps are equivalent crystallographically, the step retreat is isotropic and the etch pits maintain the initial square shape during the whole dissolution process. However, shallow pits and deep pits exhibit a very different widening behavionr. Figure 2a shows an AFM image of a (001) phosgenite face where the two types of square pits can be clearly distinguished. The image was taken 2 min after injecting a carbonated aqueous solution. Figure $2 \mathrm{~b}$ shows an image of the same area taken 1 min later. A comparison of both images shows that the shallow monolayer pits are short lived and rapidly disappear as a result of their rapid widening and coalescence. In ternns of the whole dissolution process, the dissolution of the surface monolayers represents a rapid, but transient phenomenon. On the contrary, the number of original deep pits remains approximately constant and after a few minutes they will constitute the only pemnanent feature on the phosgenite surface. Subsequent dissolution proceeds by widening and deepening of the deep pits, leading to the development of a steady tliree-dimensional microtopography. The retreat velocity for $\langle 110\rangle$ steps that boumd the deep etch pits is consistently aronnd $1.3 \mathrm{~nm} \mathrm{~s}^{-1}$. It is worth noting that even though the initially cleaved (001) faces show a high variability in the orientatiou and density of steps, only the dissolution of the deep etch pits by the retreat of $\langle 110\rangle$ steps is kinetically relevant to the dissolution on such a face. However, it is clear that the whole dissolution process of phosgenite crystals will be controlled by the contribution of the dissolution of all morphologicaly important faces (i.e., (001), (100), and (110)) and especially of the crystal edges and corners.

The dissolution of the phosgenite (001) face, with the formation of two types of etch pits, is similar to that reported by Liang et al. (1996) for the (1014) cleavage plane of calcite. In both cases the persistence of the deep etch pits some minutes after the surface is exposed to the solution, and the dissolution by retreat of single layer steps, is observed However, the different symmen of phosgenite (001) and calcite $\{10 \overline{1} 4\}$ surfaces is reflected in differences in the geometry, orientation, and development of the pits. Therefore, while the orientation of the c-glide with respect to the (1014) face in calcite imposes a 
a)

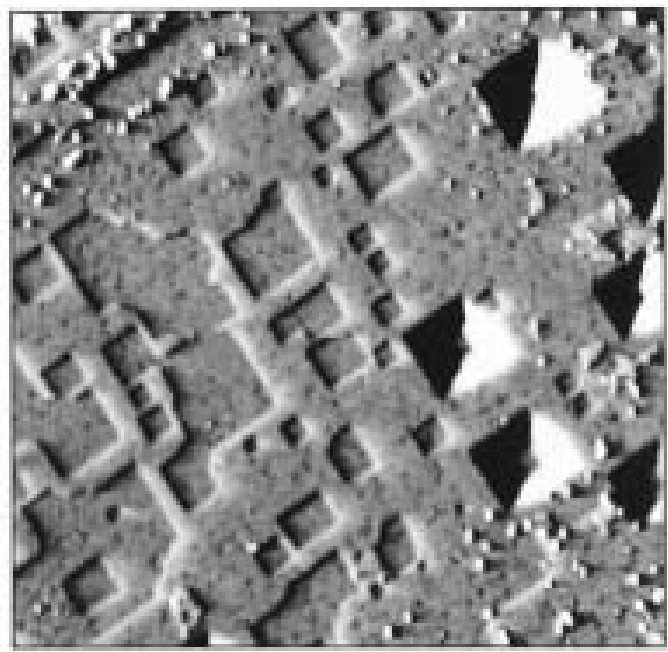

b)

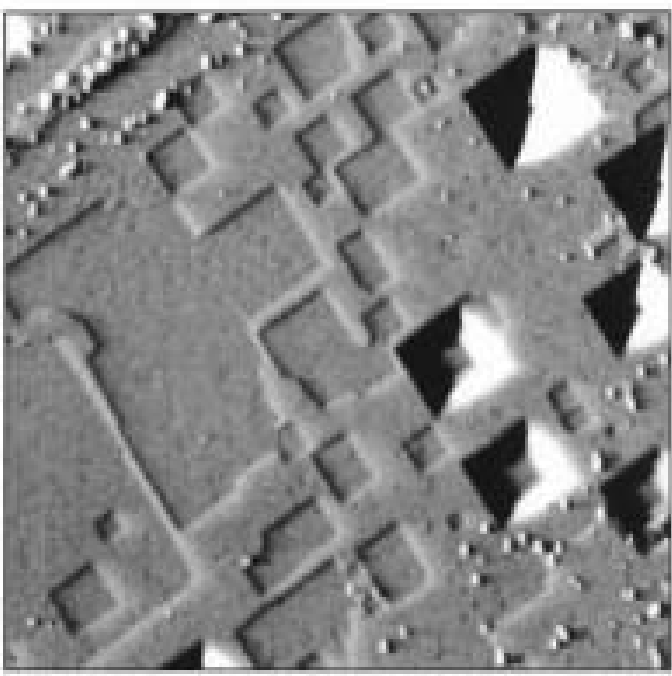

Fig. 2. Atomic force microscope images of the phosgenite (001) surface taken $1 \mathrm{~min}$ apart after exposure to a carbonated solution (initial conditions $\left.\mathbf{p H}=71 ; \boldsymbol{\alpha}\left(\mathrm{CO}_{3}^{2-}\right)=2.6 \times 10^{-8} \mathrm{~mol} / \mathrm{L}\right)$. Both imazes were taken in constant force mode while displaying the cant lever deflection signal (scan area $4 \times 4 \mu \mathrm{m}^{2}$ ). Both shallow and deep square etch pits can be observed. A comparison of the images demonstrates the different growth rates of the tw types of etch pits

highly anisotropic dissolution with two well differentiated rereating velocities of the steps, the presence of a fourfold axis perpendicular to the phosgenite (001) determines the fornation of $\langle 110\rangle$ pits, whose boumdaries retreat isotropically. Both the orientation and growth of the etch pits are consistent with the existence of symmetrically equivalent $\mathrm{Pb}-\left(\mathrm{Cl}, \mathrm{CO}_{3}\right)-\mathrm{Pb}$ chains along $\langle 110\rangle$ in the phosgenite structure.

In the range of $\mathrm{pHs}$ and $\mathrm{Na}_{2} \mathrm{CO}_{3}$ concentrations of the initial solutions used in this work, no significant differences in these microtopographic dissolution features have been observed. However, as described in Section 3.3., the $\mathrm{pH}$ of the initial solution does correlate with the nucleation density of cerussite and on subsequent dissolution phenomena near the nucleating cerussite individuals.

\subsection{Cerussite Crystallisation}

Some time after injecting the aqueons phase, cerussite crystals begin to nucleate on the phosgenite (001) surface. Cerussite nucleation occurs preferentially on specific sites on the phosgenite surface, notably on step edges. Althongh an accurate value of nucleation rate is difficult to obtain, AFM measurements of the nucleation density allow an indirect estimate to be made. Nucleation density seems to correlate with the initial $\mathrm{pH}$ (and $\mathrm{Na}_{2} \mathrm{CO}_{3}$ concentration) of the aqueous solution, increasing as the initial $\mathrm{pH}$ increases. Typical values range between 0.01 nuclei $/ \mu \mathrm{m}^{2}$ (pure water at atmospheric $\mathrm{pCO}_{2}, \mathrm{pH} 5.7$ ) and 0.03 nuclei $/ \mu \mathrm{m}^{2}\left(\mathrm{Na}_{2} \mathrm{CO}_{3}\right.$ solution, $\left.25 \mu \mathrm{mol} / \mathrm{L}, \mathrm{pH} 7.1\right)$.

Cerusxite crystals exhibit a pseudohexagonal tabular habit. Goniometric measurements carried out on the AFM images indicate that cerussite morphology is defined by $\{010\}$ as the main form, with $\{110\}$ and $\{100\}$ as secondary forms (Franke et al., 1981). The orientation of the cerussite crystals on the phosgenite surface appears to be random. Figure 3 shows a cerussite crystal on the phosgenite (001) face. As can be observed from the surface topography, the (010) face of the cerussite crystal grows according to a spiral growth mechanism. A number of spirals contribute to the formation of the face. The rounded shape of the spirals and the wavy edges of the steps indicate that the supersaturation in the growth medium with respect to cerussite is relatively high.

The most notable feature associated with the nucleation of cerussite is the marked change in the topography of the surrounding phosgenite surface. Phosgenite dissolution is accelerated around the growing crystals and the rate of cerussite growth in turn increases. New etch pits open in the phosgenite and rapidly expand and deepen. This phenomenon can be observed by comparing Fignres 2 and 3 . Figures $3 a$ and $3 b$, taken $3.4 \mathrm{~min}$ apart, also show the development of irregular dissolution fronts. The rate of expansion of the etch pits is around $4.3 \mathrm{~nm} \mathrm{~s}^{-1}$, three times faster than the average retreat velocity for the $\langle 110\rangle$ steps during dissolution in absence of cerussite. The area of influence of the growing crystals on the retreat velocity of the steps has a radius of about $2 \mu \mathrm{m}$ around each individual. As the di ssolution rate increases, the size of the cerussite crystals increases as does their area of influence.

\section{EVOLUTION OF SUPERSATURATION DURING THE DISSOLUTION_PRECIPITATION PROCESS}

Phosgenite dissolution results in the enrichment of $\mathrm{Pb}^{2+}$ and $\mathrm{CO}_{3}^{2-}$ in the aqueous solution surrounding the phosgenite surface. This, together with the very low solubility product of $\mathrm{PbCO}_{3}\left(\mathrm{~K}_{\mathrm{sp}}=10^{-1313}\right.$ at $25 \mathrm{C}$; Näsänen et al., 1961), results in a sharp increase of the supersaturation of the solution with respect to cerussite. As a result, some time after the phosgenite has been dissolving, the critical supersaturation for cerussite is reached for cerussite crystals nucleating on the (001) phosgenite surface.

To better understand this behaviour, we calculate the saturation state for cerussite and phosgenite and the $\mathrm{pH}$ was calculated as a function of the amount of dissolved phosgenite. The saturation state was computed according to the expression: $\boldsymbol{\beta}=\mathrm{II} \boldsymbol{\alpha}_{i}^{\nu i} / \mathrm{K}_{s p}$, where II $\boldsymbol{\alpha}_{i}^{\nu i}$ is the ionic activity product, $\nu_{i}$ is the stoichiometric number of ion $i$ in the solid formula, and $K_{s p}$ is the thernodynamic solubility product $\left(10^{-13.13}\right.$ for cerussite 
a)

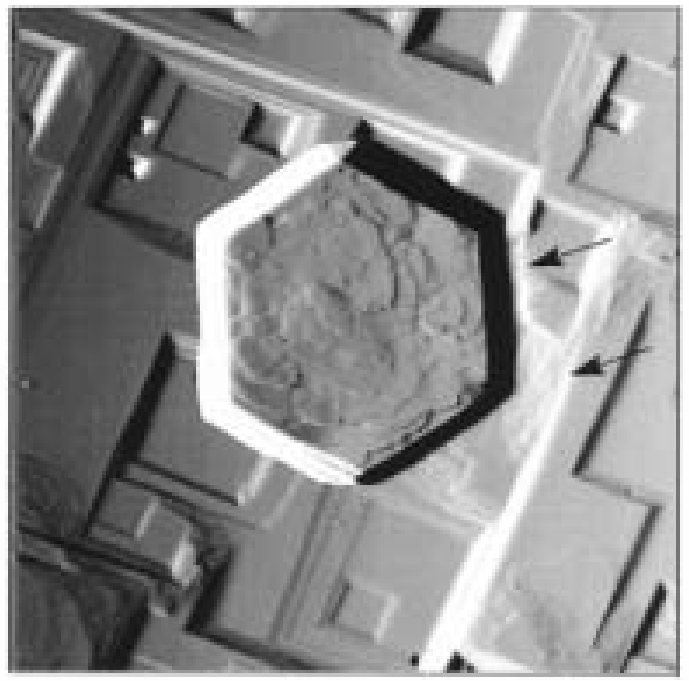

b)

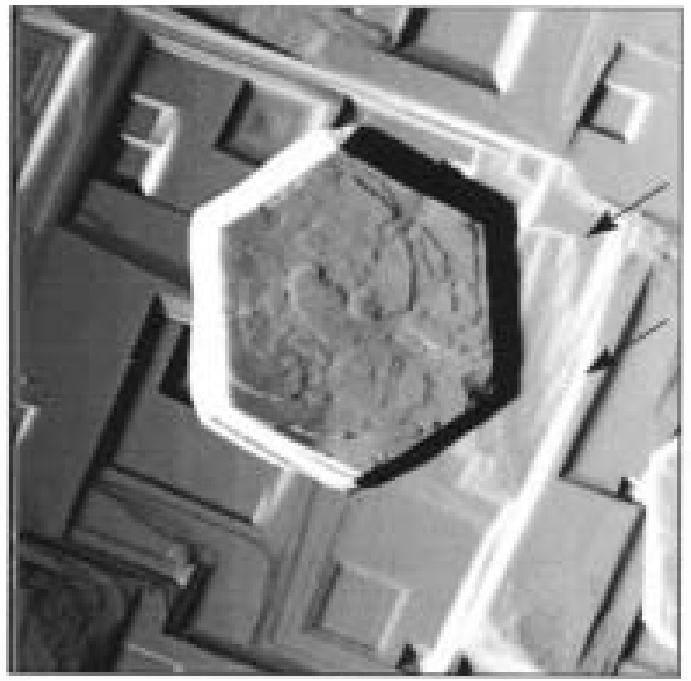

Fig. 3. (a) Tabular cerussite crystal on a dissolving phosgenite (001) surface. (b) The same area $3.4 \mathrm{~min}$ later. Initial conditions of the solution: $\mathrm{pH}=6.4 ; a\left(\mathrm{CO}_{3}^{2-}\right)=1.61 \times 10^{-9} \mathrm{~mol} / \mathrm{L}$. The rapidly retreating irregular dissolution front around the cerussite crystal is indicated by the arrows. Both AFM images are deflection images (scan area: $12 \times 12 \mu \mathrm{m}^{2}$ ). and $10^{-19.81}$ for phosgenite). For $\beta=1$ the solution is at saturation, whereas for $\beta<1$ or $\beta>1$ the solution is undersaturated or supersaturated, respectively, relative to the corresponding solid phase.

As shown in supersaturation expression an estimate of the saturation state for cerussite and phosgenite requires the activities of the aqueous ions $\mathrm{Pb}^{2+}, \mathrm{CO}_{3}^{=}$, and $\mathrm{Cl}^{-}$to be known. To determine these activities a suitable speciation model must be used to compute the concentration of the main aqueous species (free ions and ionic associations), the solution ionic strength, and the activity coefficients. The calculation involves the use of the extended Debye-Hückel formula, and has been extensively described in the literature (see for instance Truesdel and Jones, 1974). Here the following species (charged and uncharged) have been considered: $\mathrm{H}^{+}, \mathrm{OH}^{-}, \mathrm{CO}_{3}^{=}, \mathrm{HCO}_{3}^{-}, \mathrm{H}_{2} \mathrm{CO}_{3}^{0}, \mathrm{Cl}^{-}$, $\mathrm{Na}^{+}, \mathrm{NaOH}^{0}, \mathrm{NaCO}_{3}^{-}, \mathrm{NaHCO}_{3}^{0}, \mathrm{~Pb}^{2+}, \mathrm{PbCO}_{3}^{0}, \mathrm{~Pb}\left(\mathrm{CO}_{3}\right)_{2}^{=}$, $\mathrm{PbOH}^{+}, \quad \mathrm{Pb}(\mathrm{OH})_{2}^{0}, \quad \mathrm{~Pb}(\mathrm{OH})_{3}^{-}, \quad \mathrm{Pb}_{2} \mathrm{OH}^{3-}, \quad \mathrm{Pb}_{3}(\mathrm{OH})_{4}^{=}$, $\mathrm{Pb}_{4}(\mathrm{OH})_{4}^{4-}, \mathrm{Pb}_{6}(\mathrm{OH})_{8}^{4-}, \mathrm{PbCl}^{+}, \mathrm{PbCl}_{2}^{0}, \mathrm{PbCl}_{3}^{-}$, and $\mathrm{PbCl}_{4}^{=}$. Thermodynamic data for the different species were taken from Hem (1976), Wagman et al. (1982), Smith and Martell (1976), and Truesdel and Jones (1974).

Figure $4 \mathrm{a}$ shows the evolution of both $\mathrm{pH}$ and saturation states, calculated for a hypothetical situation in which no nucleation of cerussite occurs, as a function of the amount of dissolved phosgenite in pure water. As can be observed, supersaturation with respect to cerussite increases dramatically as the amount of dissolved phosgenite increases. The $\mathrm{pH}$ increases from the initial value of 5.7 to a value around 7.5 and then decreases slowly to reach a value of 7.4 , when the solution is saturated with respect to phosgenite (i.e, $\beta_{\text {phosgenite }}=1$ when dissolved phosgenite $=347.6 \mu \mathrm{mol} / \mathrm{kg}$ ). At this point the solution is highly supersaturated for cerussite $\left(\beta_{\text {cerussite }}=\right.$ 39.84) and clearly, under these conditions, phosgenite is a metastable phase. The saturation state for cerussite $\left(\beta_{\text {cerussite }}=\right.$ $1)$ is reached when the amount of dissolved phosgenite is much lower $(8.87 \mu \mathrm{mol} / \mathrm{kg})$ corresponding to a $\mathrm{pH}$ of 6.8 .

Figure $4 \mathrm{~b}$ shows a similar situation starting from an aqueous solution of $25 \mu \mathrm{mol} / \mathrm{L}$ of $\mathrm{Na}_{2} \mathrm{CO}_{3}$. In this case the initial $\mathrm{pH}$ was 7.1. When the solution is saturated with respect to phosgenite (dissolved phosgenite $=338.2 \mu \mathrm{mol} / \mathrm{kg}$ ) the supersaturation with respect to cerussite is 41.71 , and the $\mathrm{pH}$ is 7.4 . Although Figures $4 \mathrm{a}$ and $4 \mathrm{~b}$ have a similar appearance, the
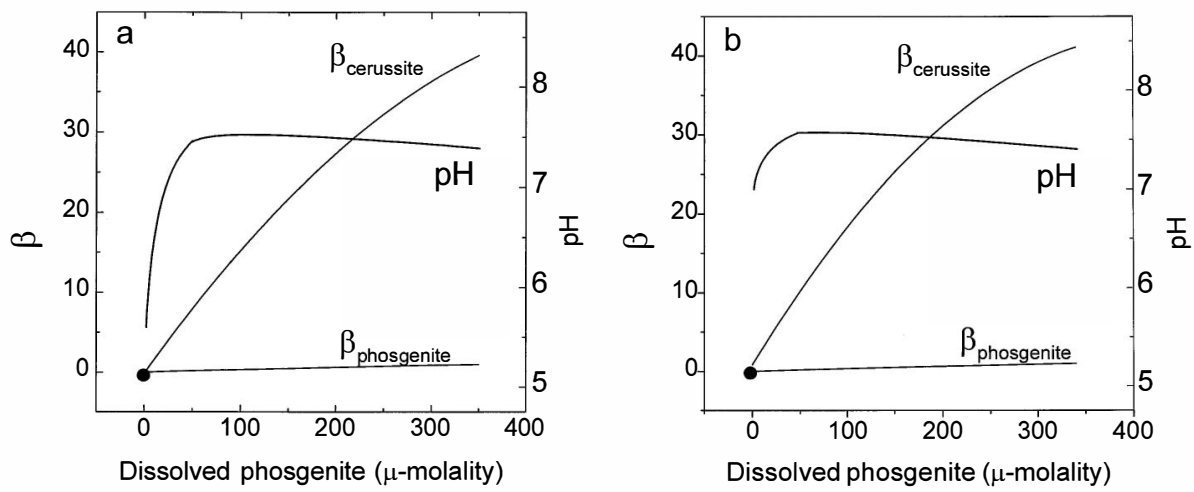

Fig. 4. Evolution of the supersaturation $\beta$ of the solution with respect to both phosgenite and cerussite as a function of the amount of dissolved phosgenite. The $\mathrm{pH}$ evolution is given by the $\mathrm{pH}$ scale on the right: (a) dissolving solution: pure water, (b) dissolving solution: $25 \mu \mathrm{mol} / \mathrm{L} \mathrm{Na}_{2} \mathrm{CO}_{3}$. 

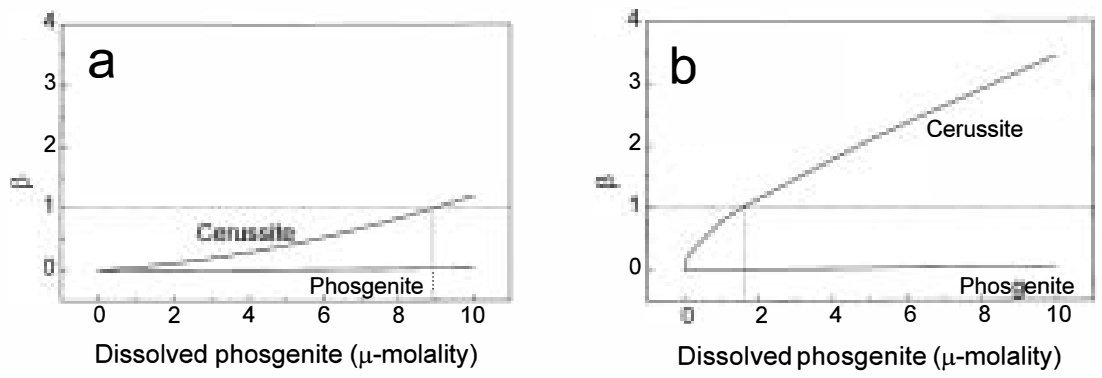

Fig. 5. Detail of the early stages of the evolution of the supersaturation $\beta$ of the solution with respect to both phosgenite and cerussite as a function of the amount of dissolved phosgenite. The intersection of the dotted lines represents the amount of dissolved phosgenite at the saturation state $(\beta=1)$ of the solution for cerussite: (a) dissolving solution: pure water, (b) dissolving solution: $25 \mu \mathrm{mol} / \mathrm{L} \mathrm{Na}_{2} \mathrm{CO}_{3}$.

main differences between them occur for low amounts of dissolved phosgenite. This is shown in Figures $5 \mathrm{a}$ and $\mathrm{b}$ which represent the saturation curves for cerussite and phosgenite on a larger scale. As can be observed, starting from an $\mathrm{Na}_{2} \mathrm{CO}_{3}-$ free solution (Fig. 5a) the saturation state for cerussite is reached later (at $8.87 \mu \mathrm{mol} / \mathrm{kg}$ dissolved phosgenite) than for a starting aqueous solution of $25 \mu \mathrm{mol} / \mathrm{L} \mathrm{Na} \mathrm{CO}_{3}$ (Fig. 5b), when the amount of dissolved phosgenite is $1.56 \mu \mathrm{mol} / \mathrm{kg}$. Moreover the slope of the supersaturation curve $\beta_{\text {cerussite }}$ is higher in the latter case (and the curve convex up instead of down), which means that even if the dissolution rate was the same, the rate of change of supersaturation with time (i.e., the supersaturation rate) for cerussite is higher.

For intermediate concentrations of $\mathrm{Na}_{2} \mathrm{CO}_{3}$ in the initial solution the behaviour is also intermediate. Table 1 displays these values for the starting aqueous solutions used in the present experiments. As can be seen, the amount of dissolved phosgenite at which cerussite saturation is reached decreases as the concentration of $\mathrm{Na}_{2} \mathrm{CO}_{3}$ in the initial solution (and the initial $\mathrm{pH}$ ) increases. At the same time, the cerussite supersaturation rate increases with the initial $\mathrm{Na}_{2} \mathrm{CO}_{3}$ content. This explains the dependence of the nucleation density of cerussite on the initial $\mathrm{Na}_{2} \mathrm{CO}_{3}$ concentration in the aqueous solution. When nucleation occurs, as in the present experiments under a changing supersaturation, the rate of creation of supersaturation determines the value of the supersaturation threshold at the nucleation time (Putnis et al. 1995). A higher initial $\mathrm{Na}_{2} \mathrm{CO}_{3}$ concentration therefore results in a higher supersaturation threshold for nucleation. As the nucleation rate depends on this supersaturation threshold, the nucleation density increases with the initial $\mathrm{Na}_{2} \mathrm{CO}_{3}$ concentration.

\section{DISCUSSION}

A number of features of this dissolution-precipitation reaction merit particular comment. First, the initial formation of cerussite happens after a period of increase in concentration of the solution sufficient for nucleation. Second, the nucleation rate of cerussite depends on the rate at which the supersaturation of the solution changes, and third, the rate of dissolution of phosgenite depends on the presence of the growing cerussite; in turn, increasing dissolution of phosgenite increases the rate of cerussite growth. Cerussite growth further undersaturates the solution with respect to phosgenite and maintains its continued dissolution. This type of feedback, where the product of a reaction favours its own production is termed autocatalysis (Prigogine, 1980; Flicker and Ross, 1974; Fisher and Lasaga, 1981). Such reactions are also characterised by an induction period, as observed in our experiments. Autocatalysis has been widely recognised in industrial chemical reactions in which dissolution-precipitation takes place. The conditions required for autocatalysis and the mechanisms operating have been extensively described by Anderson et al (1998a, b). One of the typical autocatalytic processes that these authors describe involves a new phase growing on the surface of the parent and acting as a sink because it lies inside of the diffusion distance. This is clearly recognisable in our phosgenite-cerussite dissolution-crystallisation AFM experiments.

The deduction that the phosgenite-cerussite reaction has the hallmarks of autocatalysis has a number of important implications which may also have general relevance to other dissolution-precipitation reactions. Autocatalysis is a feature of socalled complex behaviour in which nonlinear kinetic behaviour leads to phenomena such as: (i) stationary nonequilibrium states where the concentrations of the reactants and products are constant while the system is far from equilibrium; and (ii) self-organisation and pattern formation (Nicolis, 1989).

Although the phosgenite-cerussite dissolution-crystallisation reaction can be considered as a very simple chemical process, the conditions for possible complex behaviour seem to be fulfilled. First, a permanent nonequilibrium state is ensured by the very low solubility of both phases, which ensures that growth and dissolution occur at high supersaturation levels. Second, it is probable that at least one of the rates is nonlinear as a consequence of the second or higher order of the growth and dissolution laws as a function of supersaturation and undersaturation, respectively (Fisher and Lasaga, 1981; Billingham and Coveney, 1993).

Under the experimental conditions used in this work, we have observed a significant enhancement of the dissolution rate of phosgenite once cerussite has nucleated on its surface. Both the development of deep etch pits and the rapid removal of the phosgenite surface are difficult to explain in the case of a compound with such low solubility $\left(K_{\mathrm{sp}}=10^{-19.81}\right)$ if the simultaneous growth of cerussite is not considered. At some stage in this enhancement process a balance can be achieved between the rates of dissolution and rates of precipitation. For 
different experimental conditions, particularly for other initial parameters such as the $\mathrm{pH}$ of the solution, the $\mathrm{Na}_{2} \mathrm{CO}_{3}$ concentration, or the phosgenite microtopography, different dissolution-crystallization behaviour can be expected. Complex systems typically exhibit oscillatory reaction rates, catastrophic ransformation, and other phenomena associated with "chemical clock reactions" (Billingham and Coveney, 1993). However a detailed study of such possibilities is beyond the scope of this work. Examples of oscillatory phenomena arising from dissolution-diffusion-crystallisation processes are illustrated in Fisher and Lasaga (1981). Nahon and Merino (1997) have also described situations where the rate of growth and rate of dissolution are equalized, but suggest that stress within a rock plays a major role. We experimentally confirm here that the mere presence of a product phase on the surface of a reactant can significantly modify the rate of dissolution by affecting the local diffusion gradients in the fluid in contact with both phases. Measurements of the overall rate of reaction for a process which involves dissolution and subsequent reprecipitation must take account of the spatial and temporal relations between the two reaction steps and the mechanisms which take place on a molecular scale. Atomic force microscopy can be a very suitable technique for the detection and evaluation of microscopic coupled autocatalytic reactions.

Acknowledgments - The authors wish to thank A. Breit for carrying out the X-ray diffraction measurements and R. M. Lawinsky (TD Arkenston) for providing the phosgenite sample. This work was partially supported by the German/Spanish Joint Research Programme (Accion Integrada HA1997-126) and by the German Research Council (DFG). C. M. P. acknowledges financial support from The Spanish Ministry of Education and Culture.

\section{REFERENCES}

Abdul-Samad F., Thomas J. H., Williams P. A., Bideaux R., and Symes R. F. (1982). Mode of formation of some rare copper (II) and lead (II) minerals from aqueous solution, with particular reference to deposits at Tiger, Arizona. Trans. Met.

Anderson J. G., Doraiswamy L. K., and Larson M. A. (1998a) Microphase-assisted autocatalysis in a solid-liquid reaction with a precipitating product-I. Theory. Chem.

Anderson J. G., Larson M. A., and Doraiswamy L. K. (1998b) Microphase-assisted autocatalysis in a solid-liquid reaction with a precipitating product-II. Experimental. Chem. 2458.

Billingham J. and Coveney P. V. (1993) Simple chemical clock reactions: Application to cement hydration. J. Chem.

Trans. 89, 3021-3028

Bosbach, D., Hall Ch., Putnis A. (1998) Mineral precipitation and dissolution in aqueous solution: In situ microscopic observations on barite $(\mathbf{0 1})$ with atomic force microscopy. Chem.

160

Cardew P. T., and Davey R. J. (1985) The kinetics of solvent-mediated phase transformations. Prec

Edwards R., Gillard R. D., Williams P. A., and Pollard A. M. (1992) Studies of secondary mineral formation in the pbO- $\mathrm{H}_{2} \mathrm{O}-\mathrm{HCl}$ system. Min. Mag.

Fisher G. W. and Lasaga A. C. (1981) Irreversible thermodynamics in petrology. In Kinetics of Geechemical Processes (eds. A. C. Lasaga and R. J. Kirkpatrick) Rev.
Flicker M. and Ross J. (1974) Mechanism of chemical instability for periodic precipitation phenomena. $J$. Chem.

Franke W., Lenk K., Ittyachen M. A., and Mohanan Pillai K. (1981) The morphology of cerussite $\mathrm{PbCO}_{3}$ grown in silica gel and on hydrothermal conditions. $J$. Cryst.

Giuseppetti G. and Tadini C. (1974) Reexamination of the crystal structure of phosgenite, $\mathrm{Pb}_{2} \mathrm{Cl}_{2} \mathrm{CO}_{3}$. Tschennaks Miner. Petrel. Mitt. 21, 101-109.

Hem J. D. (1976) Geochemical controls on lead concentrations in stream water and sediments. Geøchim.

609.

Hillner P. E., Gratz A. J., Manne S., and Hansma K. (1992) Atomicscale imaging of calcite growth and dissolution in real time. Geelegy 20, 359-362.

Lattanzi P., and Tanelli G. (1978) Coniderazioni genetiche sulla cotunnite del giacimento a pirite di Niccioleta (Toscana). Rend. Sec. Ital. Min

Liang Y., Baer D. R., McCoy J. M., Amonette J. E., and La Femina P. (1996) Dissolution kinetics at the calcite-water interface. Geøchim. C•smechim.

Merino E. and Dewers T. (1998) Implications of replacement for reaction-transport modelling. $J$. Hydrology 209, 137-146.

Nahon D. and Merino E. (1997) Pseudomorphic replacement in tropical weathering: Evidence, geochemical consequences, and kinetic-rheological origin. Am.

Näsänen R., Merilänen P., and Leppänen K. (1961) Potentiometric determination of the solubility product of lead carbonate. Acta Chem. Scand. 15, 913-918.

Nicolis G. (1989) Physics of far-from-equilibrium systems and selforganisation. In: The New Physics (ed. P. Davies), Chap. 11, pp. 316-347. Cambridge University Press.

Overney R. M., Haefke H., Meyer E., Güntherodt H. J. (1992) Cleavage face of alkaline earth fluorides studied by atomic force microscopy. Surf. Sci. 277,

Park Ch. F. and MacDiarmid R. A. (1970) Ore depesits. Freeman

Pina C. M., Fernández-Díaz L. and Prieto M. (1996). Topotaxy relationships in the transformation phosgenite-cerussite. J. Cryst. Growth 158, 340-345.

Prigogine I. (1980) From Being to Becøming.

Putnis A., Prieto M., and Fernández-Díaz L. (1995) Fluid supersaturation and crystallization in porous media. Geel. Mag.

Saether O. M., Bølviken B., Lảg J., and Steinnes E. (1988) Concentration and chemical form of lead during natural transportation in groundwater. Chem.

Sangwal K. (1987) Etching of crystals: Theory, experiment, and applications. In Defects in Selids (eds. S. Amelinckx and J. Nihoul), Vol. 15, p. 497. North-Holland Physics.

Sangwal K., Sizova N. L., and Urusovskaya A. A. (1977) Causes ofthe formation of etch pits of different size and morphology on $\{100\}$ faces of CsI crystals. Wrist.

Smith R. M. and Martell A. E. (1976) Critical stability constants. In Inerganic Complexes,

Stipp S. L. S., Gutmannsbauer W., and Lehmann T. (1996) The dynamic nature of calcite surfaces in air. $\mathrm{Am}$.

Truesdel A. H. and Jones B. F. (1974) WATEQ, a computer program for calculating chemical equilibria in natural waters for calculating chemical equilibrium in natural waters. $J$. Res.

Von Vulté J. (1950) Die orientierten verwachsungen der Mineralien. Fortschrift

Wagman D. D. et al. (1982) The NBS tables of chemical thermodynamic properties: Selected values for inorganic and $C_{1}$ and $C_{2}$ organic substances in SI units. J. Phys. Chem.

(Suppl. 12). 